\title{
Radio Access Technology (RAT) Selection Mechanism using TOPSIS Method in Heterogeneous Wireless Networks (HWN)
}

\author{
Farhat Anwar, Mosharrof H. Masud, Burhan ul Islam Khan, Rashidah F. Olanrewaju, \\ Suhaimi A. Latif \\ Department of Electrical and Computer Engineering, International Islamic University Malaysia, \\ Kuala Lumpur, Malaysia
}

\begin{tabular}{l} 
Article Info \\
\hline Article history: \\
Received Apr 9, 2018 \\
Revised May 20, 2018 \\
Accepted Jul 11, 2018 \\
\hline
\end{tabular}

\section{Keywords:}

Heterogeneous wireless

Networks (HWN)

Multi-attribute decision making (MADM)

Radio access technology (RAT)

TOPSIS method

\begin{abstract}
In next-generation wireless networks, a Multi-Mode Device (MMD) can be connected with available Radio Access Technology (RAT) in a Heterogeneous Wireless Network (HWN). The appropriate RAT selection is essential to achieve expected Quality of Service (QoS) in HWN. There are many factors to select an appropriate RAT in HWN including Data rate, Power consumption, Security, Network delay, Service price, etc. Nowadays, the MMDs are capable to handle with multiple types of services like voice, file downloading, video streaming. Considering numerous factors and multiple types of services, it is a great challenge for MMDs to select the appropriate RAT. A Multi-Attribute Decision Making (MADM) method to deal with numerous attributes to achieve the expected goal is Technique for Order Preference by Similarity to Ideal Solution (TOPSIS). This research utilized TOPSIS method to evaluate its proposed algorithm to choose the proper RAT for single and dual call services. The algorithm applies users' preference of a specific RAT that varies for diverse categories of calls. It also aggregates the assigned call weight and call priority to choose the RAT for group call admission for different scenarios. The highest closeness coefficient has been considered the appropriate networks among other networks. 100 call admission into three networks has been simulated and has been observed.
\end{abstract}

Copyright $@ 2018$ Institute of Advanced Engineering and Science. All rights reserved.

\section{Corresponding Author:}

Burhan ul Islam Khan,

Department of Electrical and Computer Engineering,

International Islamic University Malaysia,

Kuala Lumpur, Malaysia.

Email: burhan.iium@gmail.com

\section{INTRODUCTION}

The next generation wireless networks are envisaged to be connected through multiple wireless links like 3G, WiFi, WiMAX and LTE etc. anywhere and at any time with the most exceptional quality of service that creates heterogeneous wireless environments. These varieties of wireless links give the options to the users of being "always best connected" where the system attempts keeping the users linked to the Internet all the time [1]. The aforementioned wireless technologies were developed to be operated individually. Due to the advancement of the wireless communications, multi-homing supportive Mobile Devices (MDs) have been introduced [2]. The primary resource of the wireless link is bandwidth that has been allocated from a wireless link to the MD. However, the bandwidth of a single link may not be always enough to operate the heavy traffic, particularly for real-time traffic like video conferencing, online gaming, High Definition (HD) TV services, etc. Hence, the available resources or bandwidth in a particular area from all available links can be integrated, and the traffic can be transmitted [3]. The most critical issue includes determining the most appropriate network for a particular user in its present situation [1]. 


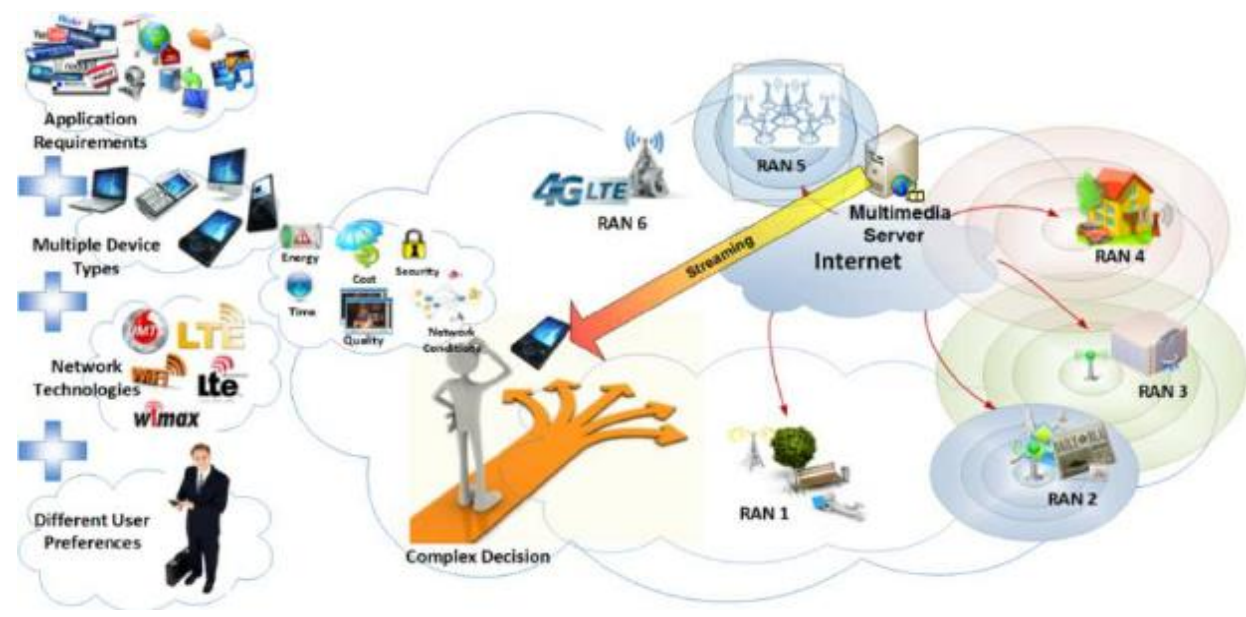

Figure 1. Heterogeneous Wireless Networks Environment [4]

The network selection criteria depend on many factors such as security, available throughput, cost, delay, jitter, reliability, etc. [5-6]. In heterogeneous wireless network environments, an MD faces difficulty while choosing the best network for connection to meet its application requirements, different user preferences, multiple device types with different capabilities among all available overlapped network technologies. Considering this multifaceted scenario, it would be better to have the options on an MD to select the best possible networks considering application requirements, their preferences and overall network conditions. Considering the issues mentioned earlier, this paper aims to provide a solution to choose the best suitable Radio Access Technology (RAT) using a method based on Multi-Attribute Decision Making (MADM). MADM methods are commonly applied to solve the multi-criteria decision problem, along with the network selection problem.

There are some popular MADM methods that have been found in the literature. Based on our findings in literature review, it can be said that Technique for Order Preference by Similarity to Ideal Solution (TOPSIS) method is relatively better for network selection due to its high sensitivity of the changes of the attributes. Hence, TOPSIS method is applied in this research to select a RAT for multiple criteria.

The rest of the paper is divided into five sections: Section 2 and 3 discuss Heterogeneous Wireless Networks and Multi-Attribute Decision Making (MADM) methods respectively. Section 4 provides an explanation about RAT Selection Mechanism using TOPSIS followed by its numerical analysis in Section 5. Finally, Section 6 concludes the paper.

\section{HETEROGENEOUS WIRELESS NETWORKS}

Heterogeneous Wireless Network (HWN) may be defined as the combination of two or more wireless resources such as Wireless Fidelity (WiFi), World Interoperability for Microwave Access (WiMAX) and Global System for Mobile communication (GSM) in a typical area. A typical scenario of HWN has been drawn in Figure 1 for better understanding. Heterogeneous wireless communication networks are dynamic in terms of network load, availability, energy conservation [7-8], monetary cost and network coverage [9]. A mobile device enabled with multiple interfaces can have access to any such resource on the basis of its application demand that runs on the Mobile Node (MN). The most common and accessible wireless technology comprises of the cellular technology followed by the WiFi and WiMAX technologies. Cellular technology has a broad coverage span but smaller bandwidth, WiFi has lesser coverage, but high bandwidth and WiMAX is recognised for high bandwidth as well as the area of coverage.

Currently, various network technologies like WiFi or IEEE $802.11 \mathrm{a} / \mathrm{b} / \mathrm{g}$, WiMAX or IEEE 802.16, UMTS, GPRS are merging their infrastructures with the core networks of IPv6 or IPv4. All the access technologies involved with HWN possess their individual features such as QoS support, operational costs and coverage [10]. The mobile nodes enabled with multiple interfaces may be linked to a proper interface on the basis of the requirements of the application on the mobile node and network strength [11]. The primary goal of the HWN is the capability of a mobile node to retain its present session and choose the most suitable interface while it is communicating. Every technology has its particular set of policies and rules that govern the provision of services and resources to its users. Thus, a significant issue in HWN is the design of a Radio Resource Management (RRM) system that is efficient. In general, the RRM framework may be apportioned 
using the functionalities viz. Decision Enforcement, Decision Making and Resource Monitoring. These functionalities are interrelated in such a way that the results of resource monitoring are employed in decision making after which decision enforcement takes place. Different solutions have been adopted to take this type of complicated decision and allocate the wireless resources into the MD where MADM methods have been given considerable attention in recent years particularly, TOPSIS method.

\section{MULTI-ATTRIBUTE DECISION MAKING (MADM) METHODS}

Game Multi-Attribute Decision Making (MADM) approaches have been employed to solve multicriteria decision issues, including in the fields of economics, politics, transportation and heterogeneous wireless networks. Some methods commonly used in different fields include Technique for Order Preference by Similarity to Ideal Solution (TOPSIS) [12], Simple Additive Weighting Method (SAW) [12], Multiplicative Exponential Weighted (MEW) [13], Elimination and Choice Expressing Reality (ELECTRE) $[12,14]$. Analytic Hierarchy Process (AHP) and Grey Relational Analysis (GRA).

Simple Additive Weighting (SAW) is one of the popularly employed methods of MADM. It can obtain the weighted total of the normalized form of every parameter on each candidate network. According to the problem definition, the network with the highest/lowest score is picked out as the most exceptional network in the HWN. The scores may be calculated based on available bandwidth, network congestion and delay, monetary costs and other network parameters. The score function is obtained by taking the total of the weighted, normalized forms of the above parameters, and the user can modify the weights by changing the parameters. For scaling various features of diverse units into analogous digital representations, distinct normalization functions are utilized, like logarithmic, linear piecewise and exponential functions [15]. This is a simple method and primarily employed in the MADM field. However, one of the significant SAW limitations is that the difference between two parameters may be severely exceeded by considerably good value. For instance, if the network has a low throughput, but the price is equally reasonable, a network with better throughput can be selected through a slightly more expensive network.

Suppose we take a candidate network and a list of every network, so we shall have an $\mathrm{n}$ parameter list, and for every candidate network i, a score can be found by utilizing the Equation 1.

$$
S A W_{i}=\sum_{j=1}^{n} w_{j} r_{i j}
$$

Where $r_{i j}$ represents the normalized performance rating of parameter $\mathrm{j}$ on network $\mathrm{i}$, and $w_{j}$ denotes weight of parameter j. Generally, higher the score value, the more desirable the candidate network.

The synthetic shortcomings have been analyzed from the SAW method, so a method of using Multiplicative Exponential weighting (MEW) or Weighted Product (WP) in the decision mechanism is proposed [15]. On the whole, MEW is an MADM method which employs multiplication to connect the network parameter levels [13]. The author conducted an empirical test and found that the results of the SAW method were incorrect, but the results using the MEW method were accurate. In the HWN scenario, the MEW method has been utilized in the field of energy saving access network selection. The greater the value of a MEW, the more preferred alternatives are chosen for best results. MEW is not sensitive to the parameters changing and therefore, the expected results are not achieved. For instance, a score is obtained for every candidate network $\mathrm{i}$ by making use of Equation 2. Equation 2 below this line where ${ }^{r_{i j}}$ denotes the normalized performance rating of parameter $\mathrm{j}$ on network $\mathrm{i}$, and ${ }^{w_{j}}$ specifies the weight of parameter $\mathrm{j}$. The higher the score value, the more desirable the candidate network.

$$
M E W_{i}=\prod_{j=1}^{n} r_{i j}^{w_{j}}
$$

Technique for Order Preference by Similarity to Ideal Solution (TOPSIS) [12], which is similar to the ideal solution, is another popular method that works on the principle that the candidate network chosen is nearest to the ideal solution possible and furthest from the worst solution possible. The worst and ideal solutions are computed by employing the worst and best values possible for every parameter and is shown in Equation 3. The TOPSIS method was used [16-17] for ranking the candidate networks as per their proximity 
to the best solution. The parameters that were taken into consideration for the decision matrix include QoS level, available bandwidth, security level, total bandwidth, cost per byte, utilization, loss, jitter and delay [16-17]. The outcome reveals that TOPSIS is sensitive to parameter values and user preferences.

$$
\operatorname{TOPSIS}_{i}=\frac{\text { worstsolution }_{i}}{\text { idealsolution }_{i}+\text { worstsolution }_{i}}
$$

The Elimination and Choice Expression Reality (ELECTRE) [12, 14] is yet another MADM approach that is built on pairwise comparison between candidate network parameters. The concepts of consistency and inconsistency are employed for measuring the dissatisfaction and satisfaction of decision makers while evaluating the candidate networks. Generate two types of lists, such as a Consistency Set (CSet), that comprises of a series of parameters which indicate the superiority of the current network over all other candidate networks, and that a set of inconsistencies (DSet) is defined, that offers a parameter list for the present network worse than the remaining candidate networks. Use CSet and DSet to build two corresponding matrices. To represent the favoured network, elements of every matrix are equated to two thresholds: Cthreshold and Dthreshold. Pair-wise comparisons are used separately between the various options of each standard and can be complete or incomplete.

Table 1. Summary of MADM Methods

\begin{tabular}{|c|c|c|c|c|}
\hline No. & MADM Method Name & Methods & Advantages & Disadvantages \\
\hline 1. & $\begin{array}{lr}\text { Simple } & \text { Additive } \\
\text { Weighting } & \text { Method } \\
(\text { SAW }) & \end{array}$ & $\begin{array}{l}\text { A weighted sum has been used } \\
\text { to normalize the form of each } \\
\text { parameter on all candidate } \\
\text { networks. }\end{array}$ & $\begin{array}{l}\text { This is a simple method and } \\
\text { primarily employed in the } \\
\text { field of MADM. }\end{array}$ & $\begin{array}{l}\text { Two different } \\
\text { parameters may } \\
\text { differ severely by } \\
\text { considerably good } \\
\text { value. }\end{array}$ \\
\hline 2. & $\begin{array}{l}\text { Multiplicative } \\
\text { Exponential Weighted } \\
\text { (MEW) }\end{array}$ & $\begin{array}{l}\text { It uses multiplication to connect } \\
\text { network parameter levels. }\end{array}$ & $\begin{array}{l}\text { The greater the value of a } \\
\text { MEW, the more preferred } \\
\text { alternatives are chosen for } \\
\text { best results. }\end{array}$ & $\begin{array}{l}\text { Not sensitive to the } \\
\text { parameters } \\
\text { changing. }\end{array}$ \\
\hline 3. & $\begin{array}{l}\text { Technique for Order } \\
\text { Preference } \\
\text { Similarity to Ideal } \\
\text { Solution (TOPSIS) }\end{array}$ & $\begin{array}{l}\text { The selected candidate network } \\
\text { is nearest to the ideal solution } \\
\text { possible and far from the worst } \\
\text { solution possible. }\end{array}$ & $\begin{array}{l}\text { The worst and ideal solutions } \\
\text { are computed by employing } \\
\text { the worst and best possible } \\
\text { values. }\end{array}$ & $\begin{array}{lr}\text { TOPSIS } & \text { is } \\
\text { sensitive } & \text { to } \\
\text { parameter } & \text { values } \\
\text { and } & \text { user } \\
\text { preference. } & \end{array}$ \\
\hline 4. & $\begin{array}{l}\text { The Elimination and } \\
\text { Choice Expressing } \\
\text { Reality (ELECTRE) }\end{array}$ & $\begin{array}{l}\text { The concepts of consistency and } \\
\text { inconsistency are utilized for } \\
\text { measuring the dissatisfaction } \\
\text { and satisfaction of decision } \\
\text { makers. }\end{array}$ & $\begin{array}{l}\text { It uses alternative methods } \\
\text { for pairwise comparison } \\
\text { under each standard. }\end{array}$ & \begin{tabular}{l}
\multicolumn{2}{l}{ Outranking } \\
relations may be \\
complete \\
incomplete.
\end{tabular} \\
\hline 5. & $\begin{array}{l}\text { Analytic Hierarchy } \\
\text { Process (AHP) }\end{array}$ & $\begin{array}{l}\text { The AHP method calculates the } \\
\text { relative weights of different } \\
\text { parameters employed in the } \\
\text { decision model. }\end{array}$ & $\begin{array}{l}\text { It computes the highest } \\
\text { similarity to the best solution } \\
\text { and was chosen as the target } \\
\text { network. }\end{array}$ & $\begin{array}{l}\text { Inconsistent results } \\
\text { can occur when the } \\
\text { AHP is used. }\end{array}$ \\
\hline
\end{tabular}

The other two commonly used MADM approaches are Grey Relational Analysis (GRA) and Analytic Hierarchy Process (AHP). The thought behind the analytic hierarchy process is to decompose a complex problem into a hierarchical structure that is easy and simple to solve a sub-problem, while the GRA method sorts the candidate networks and chooses the one with the highest ranking. AHP is used for determining the weight of every criterion: delay, bandwidth, jitter, response time, cost, packet loss rate, bit error rate (BER), and security. However, it has been reported that inconsistencies may occur when using AHP [18]. The AHP method computes the relative weights of several parameters utilized in the decision model, while GRA gives priority to the network. The network having the highest value of Grey Relational Coefficient was believed to be in the closest proximity to the ideal solution and was thus chosen as the target network. A summary of the MADM methods has been listed in Table 1.

The AHP method is utilized for computing the weights for various criteria like delay, throughput, packet loss, jitter, security, cost, total bandwidth, cost per byte, utilization, allowed bandwidth, packet loss, packet jitter and packet delay [19-20].

A comprehensive review has been done about the sensitivity and the degree of influence for eight criteria of an Australian university students' scholarship decision making using the aforementioned MADM methods shown in Figure 2 [20]. 


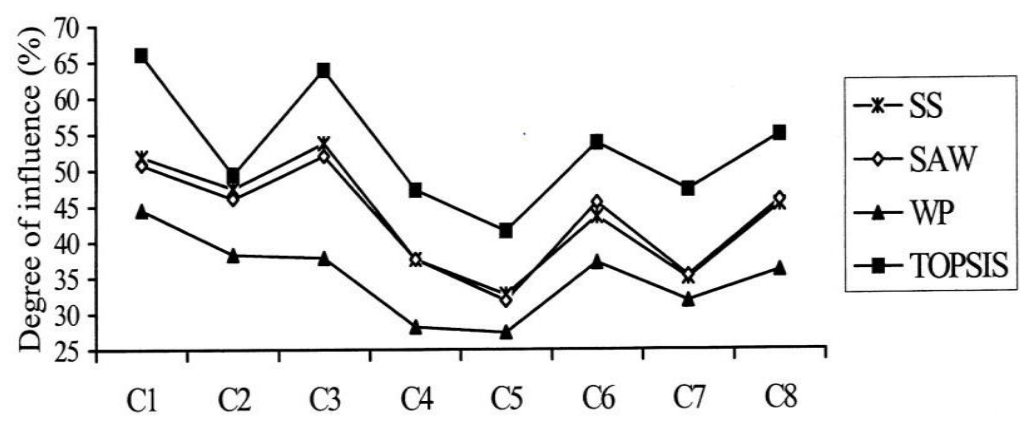

Figure 2. A Comprehensive Analysis among MADM Methods [20]

Simple Summation (SS), SAW, Weighted Product (WP) or MEW and TOPSIS methods have been used to find the best candidate for the scholarship. It can be shown that TOPSIS method has the relative influence degree of individual attributes obtained by sensitivity analysis compared to other methods. Hence, this research uses the TOPSIS method for its evaluation.

\section{RAT SELECTION MECHANISM USING TOPSIS METHOD}

In an HWN environment, a multimode device (MD) user can access multiple services including voice, video streaming and web session simultaneously through available RATs in that particular area. Hence, a group RAT selection problem is followed when an individual RAT is to be chosen for multiple services of classes from several MDs. It is known that the capabilities of RAT such as battery, delay, security level provided, battery power consumption, available bandwidth, etc. vary from one to another. Considering all these issues, selecting a RAT is a great challenge for multiple calls from MDs in an HWN.

Multiple Criteria Design Making (MCDM) technique has been adopted from a collection of alternatives, all of which are evaluated in contrast to multiple criteria for a single call operation from MDs in HWN through multiple RATs. For a group call operation, Multi Criteria Group Decision Making (MCGDM) uses the preference information on alternatives supplied by decision makers or experts and gathered to establish a collective opinion.

Mathematically, MCGDM can be designed using a finite set of possible alternatives,

$X=\left\{x_{1}, x_{2}, \ldots \ldots . . ., x_{n}\right\},(n \geq 2)$

to be ranked from worst to best, based on a group of criteria,

$$
\begin{aligned}
& C=\left\{c_{1}, c_{2}, \ldots \ldots \ldots, c_{n}\right\},(k \geq 2), \text { by a collection of decision makers, } \\
& D=\left\{d_{1}, d_{2}, \ldots \ldots \ldots, d_{n}\right\},(m \geq 2)
\end{aligned}
$$

All the decision makers present their preference information on alternatives, and each one of those is combined to establish a collective opinion (decision). Several solutions have been proposed to address the MCDM and MCGDM problems where TOPSIS method can be used for both problems in HWN environment.

Problem Definition

Let $R=\left\{r^{1}, r^{l}, \ldots \ldots \ldots, r^{|R|}\right\},|R| \geq 2$

be the RAT set in HWN and let

$S=\left\{s^{1}, s^{i}, \ldots \ldots \ldots, s^{|S|}\right\},|S| \geq 1$

be the service set sustained in HWN.

Let $S^{t}=\left\{s_{t}{ }^{1}, s_{t}{ }^{k}, \ldots \ldots \ldots, s_{t}^{\left|S^{t}\right|}\right\},\left|S^{t}\right| \geq 1$

be the set of call (decision makers) from multimode terminal, $M^{t}$, which participates to choose a RAT from a group of RATs available, $R^{t}$ which may sustain the collection of calls from $M^{t}$, where, $R^{t}=\left\{r_{t}^{1}, r_{t}^{j}, \ldots \ldots \ldots, r_{t}^{|R|}\right\},|R| \geq 1$

Let $C=\left\{c^{1}, c^{u}, \ldots \ldots \ldots, c^{|C|}\right\},|C| \geq 1$, represent the criteria set for the most appropriate RAT for the incoming call(s) from multiple channels in HWN. Notably, $|\mathrm{X}|$ specifies the cardinality of X. 
Let $W^{t, i}=\left\{w_{t, i}^{1}, w_{t, i}^{j}, \ldots \ldots \ldots, w_{t, i}{ }^{|C|}\right\}$ signifies the user specified weight set for the RAT selection criteria, where $W_{t, i}{ }^{u}$ is the weight criterion, $C^{u}$, for call $s_{t}^{i}$ from $M^{t}$. Every individual user shall put his preference for the specific RAT for every class of calls. The weight denotes the relative significance of every criterion for every category of call to the client. Weight may be scaled on a 10 point scale (0-9) with 0 representing the minimum and 9 representing the maximum weight defined by the MD users for a specific class of call. Finally, $P^{t}=\left\{P_{t}^{1}, s_{t}{ }^{i}, \ldots \ldots . . ., s_{t}{ }^{\left|S^{t}\right|}\right\}$ denotes the priority of each call in $S^{t}$. The values of call priority are listed in Table 2 .

Table 2. Call Priority Scale

\begin{tabular}{lc}
\hline Call Priority & Values \\
\hline Very low & 1 \\
Low & 2 \\
Medium & 3 \\
High & 4 \\
Very high & 5 \\
\hline
\end{tabular}

The complete process is classified into some phases listed below.

Phase 1: Specify the call set, $S^{t}$, from $M^{t}$ for which a RAT is to be chosen. For example, voice call, file downloading and video streaming could be types of call. Then, specify the $P^{t}$ and $W^{t, i}$.

Phase 2: Build the decision matrix, $D^{t}$ for $\left|R^{t}\right|$ RATs available based on $|\mathrm{C}|$ RAT criteria. A general decision matrix has been constructed in the Equation 4.

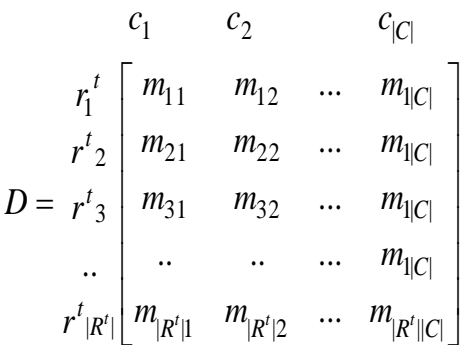

Where $m_{j, u}$ denotes the performance rating of $\operatorname{RAT} r_{j}^{t}\left(j=1,2,3 \ldots .\left|R^{t}\right|\right)$ on different criteria $c_{u}(u=1,2,3 \ldots \ldots|C|)$. It can be noted that the values of decision matrix could be both linguistic and numerical values where the linguistic terms will be converted into crisp values using standard fuzzy logic formulas that has been listed in Table 3 .

Table 3. Fuzzy Values Converted Into Crisp Numbers

\begin{tabular}{lc}
\hline Fuzzy Name & Fuzzy Values \\
\hline Very High & 0.909 \\
High & 0.717 \\
Medium & 0.50 \\
Low & 0.283 \\
Very Low & 0.091 \\
\hline
\end{tabular}

Phase 3: The decision matrix needs to be normalized due to measure every criterion in dimensionless approach. Each of the normalized vectors can be defined as $\overline{m^{t}{ }_{j, u}}$ of the decision matrix $\overline{D^{t}}$ that can be computed in the following Equation 5 . 


$$
\overline{m_{j, u}}=\frac{m_{j, u}}{\sqrt{\sum_{x=1}^{\left|R^{t}\right|}\left(m_{j, u}\right)^{2}}}, \quad j=1,2,3, \ldots\left|R^{t}\right|, u=1,2,3, \ldots .|C|
$$

Where $\overline{m_{j, u}^{t}}$ specifies the normalized performance valued of RAT $r_{j}^{t}$ on criterion.

Phase 4: The weighing vector, $W^{t, i}$ can be defined as follows:

$$
W^{t, i}=\left\{w_{t, i}^{1}, w_{t, i}^{u}, \ldots \ldots \ldots, w_{t, i}{ }^{|C|}\right\}
$$

The user specified weight criteria need to be normalized and can be defined as.

$$
\begin{aligned}
& \bar{w}_{t, i}=\left\{\bar{w}_{t, i}{ }_{\left.t, \ldots \ldots . ., w^{u}{ }_{t, i}, \ldots \ldots \ldots \ldots . . .\left.w^{|C|}\right|_{t, i}\right\}}\right. \\
& \bar{W}_{t, i}{ }^{u}=\frac{w_{t, i}{ }^{u}}{\sum_{x=1}^{|C|} w^{x}{ }_{t, i}}, \quad \forall u=1,2,3, \ldots \ldots . .|C|
\end{aligned}
$$

Phase 5: Now, we need to normalize the priority vector:

$$
P^{t}=\left\{p_{t}^{1}, p_{t}^{i}, \ldots \ldots \ldots, p_{t}^{\left|S^{t}\right|}\right\}
$$

The call priority vectors are normalized as follows:

$$
\begin{aligned}
& \bar{P}^{t, i}=\left\{\bar{p}^{1}, \ldots \ldots \ldots, \bar{p}_{t}{ }_{t}, \ldots \ldots \ldots \ldots . . . \bar{p}_{t}\left|S^{t}\right|\right\} \\
& \bar{P}_{t}{ }^{i}=\frac{p_{t}{ }^{i}}{\sum_{x=1}^{\left|S^{t}\right|} w^{x}{ }_{t}}, \quad \forall i=1,2,3, \ldots \ldots . .\left|S^{t}\right|
\end{aligned}
$$

Phase 6: Aggregate the normalized weight and normalized priority.

$$
x_{t, u}=\frac{1}{\left|S^{t}\right|} \sum \bar{w}_{t, i}^{u} \cdot \bar{p}_{t}^{i} \quad u=1,2,3, \ldots \ldots .|C|
$$

The group weighting vector, $X^{t}$ can be computed as follows.

$$
X^{t}=\left\{x_{t, 1, \ldots \ldots \ldots .,} x_{t, u, \ldots \ldots . .} x_{t, \mid C l}\right\}
$$

Phase 7: Combine the normalized decision matrix, $\overline{D^{\prime}}$ and group weighting vector, $X^{t}$ to get weighted normalized decision matrix, $H^{l}$ as shown in Equation in 14. 


$$
\begin{aligned}
& \begin{array}{llll}
c_{1} & c_{2} & c_{|C|}
\end{array} \\
& H^{t}=\begin{array}{c}
r_{1}^{t} \\
r^{t}{ }^{t}{ }_{3} \\
. . \\
r_{\left|R^{t}\right|}^{t}
\end{array}\left[\begin{array}{cccc}
h_{11} & h_{12} & \ldots & h_{1|C|} \\
h_{21} & h_{22} & \ldots & h_{1|C|} \\
h_{31} & h_{32} & \ldots & h_{1|C|} \\
. . & . . & \ldots & h_{1|C|} \\
h_{\left|R^{t}\right| 1} & h_{\left|R^{t}\right| 2} & \ldots & h_{\left|R^{t}\right| C \mid}
\end{array}\right]
\end{aligned}
$$

Where, $h_{t, u} * \bar{m}_{j . u} \quad \forall j \in\left\{1, \ldots \ldots .\left|R^{t}\right|\right\}, u \in\{1, \ldots \ldots .|C|\}$

Phase 8: Obtain the ideal solution, $\mathrm{A}^{*}$ and the negative ideal solution A- of Ht.

$$
\begin{aligned}
& A^{*}=\left\lfloor h_{1}^{*}, h_{2}^{*}, \ldots \ldots \ldots . ., h_{|C|}^{*}\right\rfloor \\
& A^{*}=\left\{\left(\max _{j \in R^{t}} h_{j u} \mid u \in C^{\prime}\right),\left(\min _{j \in R^{t}} h_{j u} \mid u \in C^{\prime \prime}\right)\right\} \\
& A^{-}=\left\lfloor h_{1}^{-}, h_{2}^{-}, \ldots \ldots \ldots, h_{|C|}^{-}\right\rfloor \\
& \left.A^{*}=\left\{\min _{j \in R^{t}} h_{j u} \mid u \in C^{\prime}\right),\left(\max _{j \in R^{t}} h_{j u} \mid u \in C^{\prime \prime}\right)\right\}
\end{aligned}
$$

Phase 9:

$$
\begin{aligned}
& d_{t, j}^{*}=\sqrt{\sum_{j=1}^{|C|}\left(h_{j, u}-h_{u}^{*}\right)^{2}}, j=1, \ldots \ldots .,\left|R^{t}\right|, u=1, \ldots \ldots . .|C| \\
& d_{t, j}^{-}=\sqrt{\sum_{j=1}^{|C|}\left(h_{j, u}-h_{u}^{-}\right)^{2}}, j=1, \ldots \ldots .,\left|R^{t}\right|, u=1, \ldots \ldots . .|C| \\
& f_{t}^{j}=\frac{d_{t, j}^{-}}{d_{t, j}^{*}+d_{t, j}^{-}}, \quad \forall j=1,2,3 \ldots .\left|R^{t}\right|
\end{aligned}
$$

Phase 10:

The highest closeness coefficient RAT shall be chosen for the individual or group of calls in HWN environment.

\section{NUMERICAL ANALYSIS USING TOPSIS METHOD} HWN.

For numerical analysis, the following scenarios have been considered to select a suitable RAT in

Phase 1: Three types of services are considered, viz video streaming $\left(s^{v i}\right)$, file downloading $\left(s^{d l}\right)$ and voice call $\left(s^{v o}\right)$. Five criteria have been recognized for the best suitable RAT selection for every category of calls in HWN. The requirements are classified as service price (Csp), network delay (Cnd), power consumption $(\mathrm{Cpc})$, security $(\mathrm{Cse})$ and data rate $(\mathrm{Cdr})$.

Phase 2: The RAT selection criteria utilized in this numerical analysis are given in Equation 22 in the form of the decision matrix. 


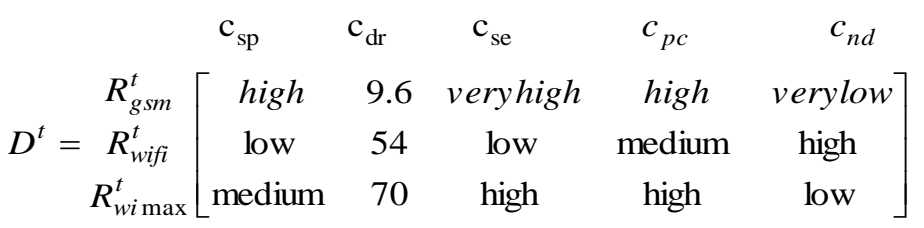

The linguistic terms can be converted into crisp values by making use of the fuzzy conversion scale described in Table 3, and the numerical values have been listed in Equation 23.

$$
\begin{aligned}
& \mathrm{c}_{\mathrm{sp}} \quad \mathrm{c}_{\mathrm{dr}} \quad \mathrm{c}_{\mathrm{se}} \quad c_{p c} \quad c_{n d} \\
& D^{t}=\begin{array}{c}
R_{\text {gsm }}^{t} \\
R_{\text {wifi }}^{t} \\
R_{\text {wimax }}^{t}
\end{array}\left[\begin{array}{ccccc}
0.717 & 9.6 & 0.909 & 0.717 & 0.091 \\
0.283 & 54 & 0.283 & 0.50 & 0.717 \\
0.50 & 70 & 0.717 & 0.717 & 0.283
\end{array}\right]
\end{aligned}
$$

Phase 3: The decision matrix has been normalized according to the formula 3.9. After applying the normalized decision matrix, the new matrix is formed and mentioned in Equation 24.

$$
\begin{aligned}
& c_{\text {sp }} \quad c_{d r} \quad c_{s e} \quad c_{p c} \quad c_{\text {nd }}
\end{aligned}
$$

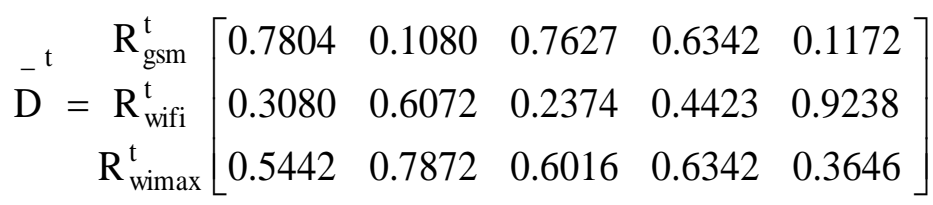

Phase 4: The user specified weight has been listed in Table 4 for three types of services, voice call service $\left(s^{v o}\right)$, file downloading service $\left(s^{d l}\right)$, and video streaming service $\left({ }^{v i}\right)$.

Table 4. Criteria Weight Scale

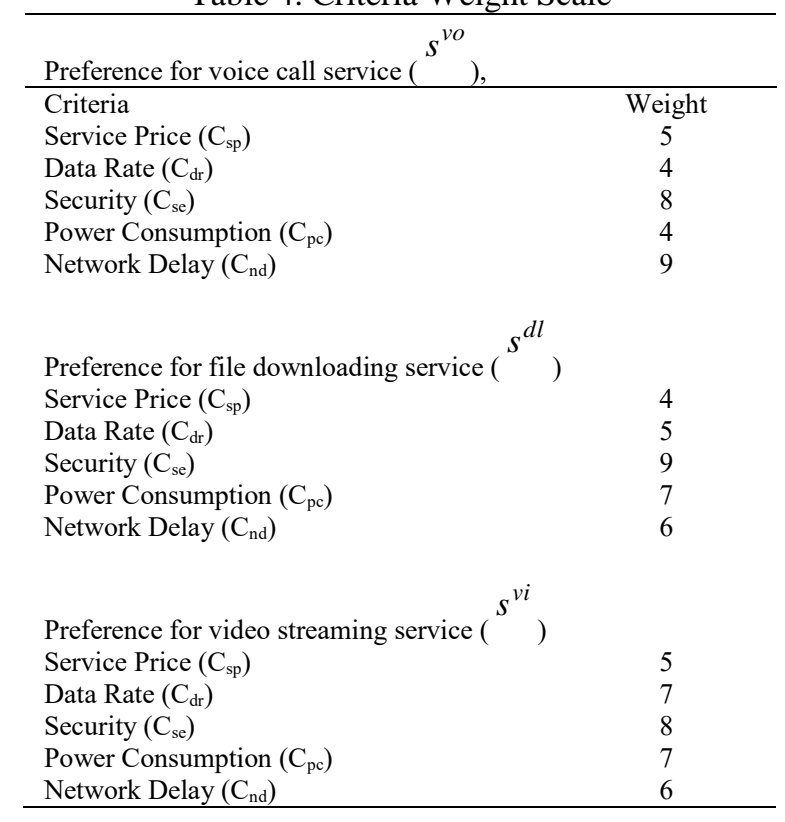

The weight has been normalized according to the formula 3.12 and formed a new data listed in equation . 


${ }_{-t}^{t}=s^{v o}{ }^{d l}\left[\begin{array}{ccccl}\mathrm{c}_{\mathrm{sp}} & \mathrm{c}_{\mathrm{dr}} & \mathrm{c}_{\mathrm{se}} & c_{p c} & c_{n d} \\ s^{v i}\end{array}\left[\begin{array}{lllll}0.1667 & 0.1333 & 0.2667 & 0.1333 & 0.3000 \\ 0.1290 & 0.1613 & 0.2903 & 0.2258 & 0.1935 \\ 0.1515 & 0.2121 & 0.2424 & 0.2121 & 0.1818\end{array}\right]\right.$

Phase 5: According to Table 5, the call priority vector for three types of services have been normalized. Five types of scenarios have been considered, and only first call priority values have been normalized according to the Equation 3.15.

Table 5. Call Priority Scale

\begin{tabular}{lc}
\hline Call Priority & Values \\
\hline Very high & 5 \\
High & 4 \\
Medium & 3 \\
Low & 2 \\
Very low & 1 \\
\hline
\end{tabular}

Five sample scenarios have been considered in Table 6 for the call priority for three types of applications; namely, voice, file downloading and video streaming. The scenarios have been considered randomly based on the application demand in different time perspectives. This TOPSIS method has been coded in Matlab, and the codes are listed in Appendix I.

Table 6. A Sample Scenario of Call Priority

\begin{tabular}{cccc}
\hline \multirow{2}{*}{ Scenario } & \multicolumn{3}{c}{ Call priority values } \\
\cline { 2 - 4 } 1 & voice & file download & video streaming \\
2 & 5 & 1 & 1 \\
3 & 5 & 5 & 5 \\
4 & 1 & 1 & 5 \\
5 & 1 & 5 & 1 \\
\hline
\end{tabular}

For the simplicity of easy understanding, the outcome of the scenario 1 has been shown here, and the remaining scenarios are computed accordingly using Matlab.

For scenario 1.

$$
p^{-}=\left[\begin{array}{l}
0.7143 \\
0.1429 \\
0.1429
\end{array}\right]
$$

Phase 6: The values of normalized weight from the Equation 4.4 and normalized call priority from the Equation 26 (for the $1^{\text {st }}$ scenario) have been aggregated according to the Equation 3.16, and a new vector has been formed listed in Equation 27.

$$
X=s^{d l}\left[\begin{array}{ccccc}
\mathrm{c}_{\mathrm{sp}} & \mathrm{c}_{\mathrm{dr}} & \mathrm{c}_{\mathrm{se}} & c_{p c} & c_{n d} \\
s^{v i}
\end{array}\left[\begin{array}{ccccc}
0.1190 & 0.0952 & 0.1905 & 0.0952 & 0.2143 \\
0.0184 & 0.0230 & 0.0415 & 0.0323 & 0.0276 \\
0.0216 & 0.0303 & 0.0346 & 0.0303 & 0.0260
\end{array}\right]\right.
$$

Phase 7: The aggregated values of $\mathrm{X}$ from the Equation 27 and $D^{-t}$ from the Equation 4.3 have been multiplied, and a new form of the matrix has been formed as shown in Equation 28. 


$$
X=s^{d l} s^{v i}\left[\begin{array}{ccccc}
\mathrm{c}_{\mathrm{sp}} & \mathrm{c}_{\mathrm{dr}} & \mathrm{c}_{\mathrm{se}} & c_{p c} & c_{n d} \\
0.0929 & 0.0103 & 0.1453 & 0.0604 & 0.0251 \\
0.0057 & 0.0140 & 0.0098 & 0.0143 & 0.0255 \\
0.0118 & 0.0239 & 0.0208 & 0.0192 & 0.0095
\end{array}\right]
$$

Phase 8: It has been determined from the Equation 28 the ideal solution, $\mathrm{A}^{*}$ and the negative ideal solution A- of Ht represented in Equation 29 andb30 respectively.

$$
\begin{aligned}
& A^{*}=\left\{\begin{array}{lll}
0.1453 & 0.0255 & 0.0239
\end{array}\right\} \\
& A^{-}=\left\{\begin{array}{lll}
0.0103 & 0.0057 & 0.0095
\end{array}\right\}
\end{aligned}
$$

Phase 9: Applying the formula of Equation 3.23 and Equation 3.24 using the values of Equation 29 and 30 , the TOPSIS outcome has been achieved.

$$
f=\underset{\mathrm{R}_{\text {wifi }}^{\mathrm{t}}}{\mathrm{R}_{\text {wsmax }}^{\mathrm{t}}}\left[\begin{array}{l}
0.7391 \\
0.7406 \\
0.7521
\end{array}\right]
$$

Phase 10:

Finally, the highest valued RAT can be selected from the available list of RATs. In this case, WiMAX is selected. As mentioned above that the calculation of scenario 1 has been shown here for the simplicity, and the remaining four scenarios have also been calculated. A simulation has been conducted for five different scenarios, and the output has been listed in table 7 .

Table 7. The closeness coefficient values for five scenarios

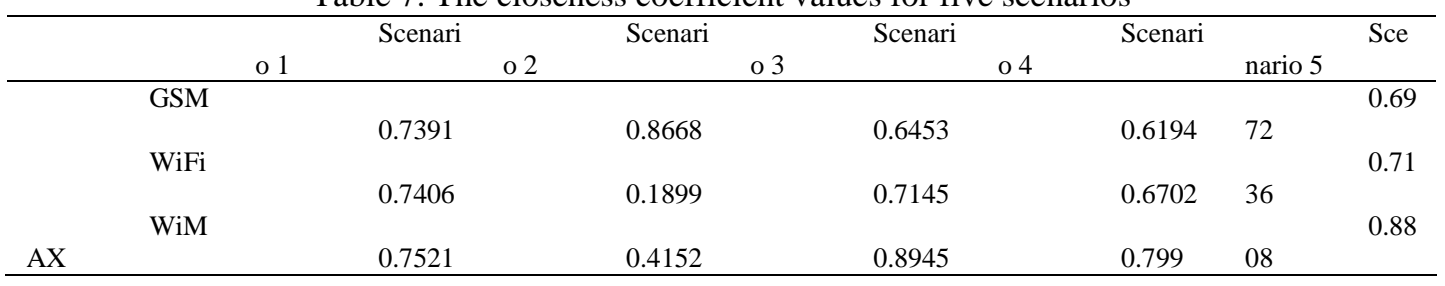

Figure 3 is the graphical representation of Table 7, where five different scenarios have been considered for three networks. It can be noted from Figure 3 for scenario 1 that, when same priorities (in this case 5) are set for voice call, file downloading and video streaming, the three networks show very close values and finally, WiMAX has been chosen due to the higher value.

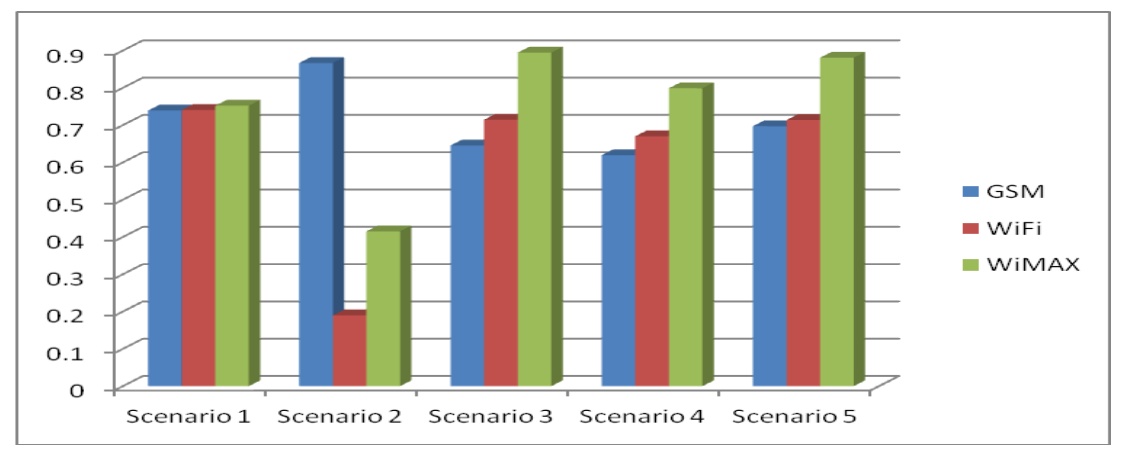

Figure 3. Selection using TOPSIS Method for various scenarios 
As TOPSIS method is very sensitive to its attributes, changes of priority values affect abruptly on network selection. For example, for the second scenario in table 6, highest priority (5) is given to voice call and lowest priority (1) to file downloading and video streaming, and the results can be shown in Figure 3 that GSM network has been selected. The priority values have been alternated for the rest of the three scenarios where the WiMAX network has been marked with highest coefficient values.

The Rate of Call Admission into each RAT

Our research has investigated the proportion of call admission into each RAT for three types of services. We have simulated 100 calls for three types of services: voice call service, file downloading service and video call service, among the three networks in HWN.

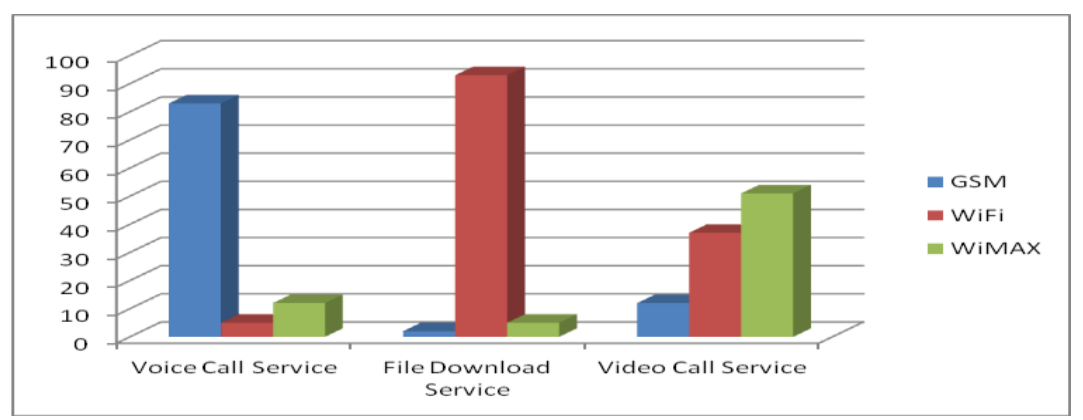

Figure 4. Number of call distribution among three networks for a single service

These three types of call services have been categorized into single service and dual service. For the single service, it can be depicted from Figure 4 that more than $80 \%$ of the calls were admitted into the GSM network for voice call service and least admitted into WiFi Networks. For file downloading service, mostly admitted at WiFi networks due to higher data rate capacity and comparatively lower price, whereas file downloading was admitted at GSM networks for low data rate capacity. Finally, the video streaming service mostly admitted into WiMAX followed by WiFi and GSM networks.

For dual service, voice and file downloading service, most were admitted to WiMAX followed by WiFi. Voice and video call service, were mostly admitted to GSM networks due to less delay. Finally, file downloading and video call service significantly admitted into WiFi followed by WiMAX due to a higher data rate.

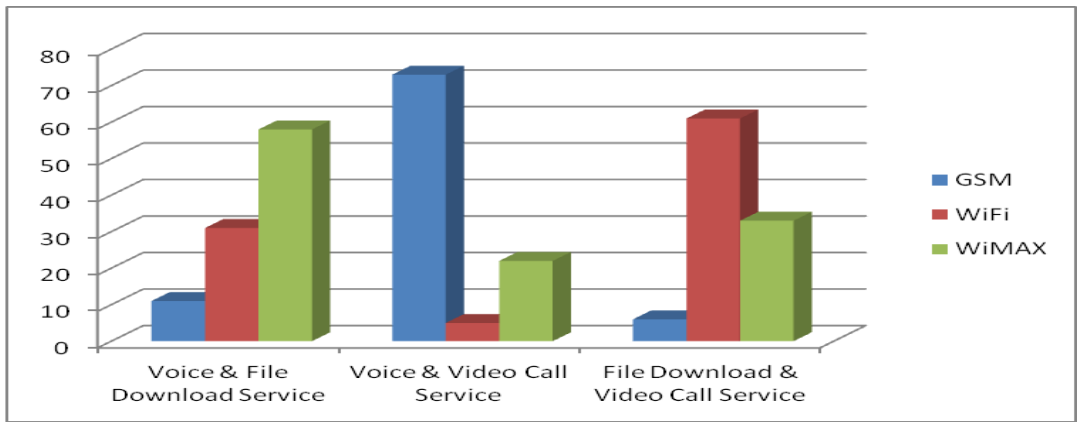

Figure 5. Number of call distribution among three networks for dual services

Appropriate RAT selection is a great challenge in HWN. Several MADM methods have been reviewed, and TOPSIS method has been selected to measure the proposed algorithm. The highest closeness coefficient is considered the appropriate RAT among other available RATs. Different call services like single and dual call services have been considered for 100 call admission among three different networks that have been shown in Figure 5. Appropriate RAT has been selected based on call service required data rate and bandwidth capacity of the RAT. 


\section{CONCLUSION}

Appropriate RAT selection is a great challenge in HWN. Several MADM methods have been reviewed, and TOPSIS method has been selected to measure the proposed algorithm. The highest closeness coefficient is considered the appropriate RAT among other available RATs. Different call services like single and dual call services have been considered for 100 call admission among three different networks. Appropriate RAT has been selected based on call service required data rate and bandwidth capacity of the RAT.

\section{ACKNOWLEDGEMENT}

This work was partially supported by Ministry of Higher Education Malaysia (Kementerian Pendidikan Tinggi) under Fundamental Research Grant Scheme (FRGS) number FRGS13-081-0322

\section{REFERENCES}

[1] Gustafsson E, Jonsson A. "Always best connected". IEEE Wireless communications. 2003 Feb; 10(1): 49-55.

[2] Masud MH, Latif SA, Alam FA. "A scheduling algorithm for bandwidth aggregation in Heterogeneous Wireless Network". 2014 International Conference on Informatics, Electronics \& Vision (ICIEV). IEEE. 2014 May 23: 1-4.

[3] Latif SA, Masud MH, Anwar F, Alam MK. "An investigation of scheduling and packet reordering algorithms for bandwidth aggregation in heterogeneous wireless networks". Middle-East Journal of Scientific Research. 2013; 16(12): 1613-1623.

[4] Trestian R, Ormond O, Muntean GM. "Game theory-based network selection: Solutions and challenges". IEEE Communications surveys \& tutorials. 2012 Oct; 14(4): 1212-1231.

[5] Song Q, Jamalipour A. "A network selection mechanism for next generation networks". IEEE International Conference on Communications, ICC 2005. IEEE. 2005 May 16; 2: 1418-1422.

[6] Fux V, Maillé P. "A rating-based network selection game in heterogeneous systems". 8th EURO-NGI Conference on Next Generation Internet (NGI), IEEE. Karlskrona, Sweden. 2012 Jun 25: 125-132.

[7] Hassan S, Nisar MS, Jiang H. "Energy preservation in heterogeneous wireless sensor networks through zone partitioning”. Indonesian Journal of Electrical Engineering and Computer Science (IJEECS). 2016 May 1; 2(2): 390-395.

[8] Dhage MR, Vemuru S. A Effective Cross Layer Multi-Hop Routing Protocol for Heterogeneous Wireless Sensor Network. Indonesian Journal of Electrical Engineering and Computer Science (IJEECS). 2018 May 1; 10(2): 664671.

[9] Zhang J, Wang Y, Liu Y, Li Q. "Nodes Deployment Scheme of Heterogeneous Wireless Sensor Network Based on Organic Small Molecule Model". Indonesian Journal of Electrical Engineering and Computer Science (IJEECS). 2015 Dec 1; 16(3): 574-582.

[10] Piamrat K, Ksentini A, Bonnin JM, Viho C. "Radio resource management in emerging heterogeneous wireless networks". Computer Communications. 2011 Jun 15; 34(9): 1066-1076.

[11] Masud MH, Anwar F, Bari SM. "A primary interface selection policy in heterogeneous networks based on QoS". $20124^{\text {th }}$ International Conference on Computer and Communication Engineering (ICCCE). IEEE. Kuala Lumpur, Malaysia. 2012 Jul 3: 706-711.

[12] Hwang CL, Yoon K. "Multiple attribute decision making: methods and applications". A State-of-the-Art Survey. New York: Springer-Verlag. 1981

[13] Adamopoulou E, Demestichas K, Koutsorodi A, Theologou M. "Intelligent access network selection in heterogeneous networks-simulation results". 2nd International Symposium on Wireless Communication Systems. 2005: 279-283.

[14] Fülöp J. "Introduction to decision making methods". BDEI-3 workshop. Washington. 2005 Nov.

[15] Nguyen-Vuong QT, Ghamri-Doudane Y, Agoulmine N. "On utility models for access network selection in wireless heterogeneous networks". NOMS Network Operations and Management Symposium. IEEE 2008 Apr 7: 144-151.

[16] Bakmaz B, Bojkovic Z, Bakmaz M. "Network selection algorithm for heterogeneous wireless environment". 18th International Symposium on Personal, Indoor and Mobile Radio Communications (PIMRC). IEEE. 2007 Sep 3: 14.

[17] Bari F, Leung VC. "Automated network selection in a heterogeneous wireless network environment". IEEE network. 2007 Jan; 21(1): 34-40.

[18] Sgora A, Vergados DD, Chatzimisios P. "An access network selection algorithm for heterogeneous wireless environments". IEEE Symposium on Computers and Communications (ISCC). 2010 Jun 22. 890-892.

[19] Mohamed L, Leghris C, Abdellah A. "A hybrid approach for network selection in heterogeneous multi-access environments". 4th IFIP International Conference on New Technologies, Mobility and Security (NTMS). 2011 Feb 7: $1-5$.

[20] Yeh CH. "A problem-based selection of multi-attribute decision-making methods". International Transactions in Operational Research. 2002 Mar 1; 9(2): 169-181. 